\title{
A INTERTESSITURA DO DRAMÁTICO COM O POLÍTICO EM A invasão, DE DIAS GOMES ${ }^{(*)}$
}

Cibele de Mello Costa Universidade Federal de Alagoas

Numa sociedade injusta, não denunciar a injustiça é contribuir, pela omissão, para que ela perdure. Não tomar partido é ficar do lado do mais forte. Daí não existir um teatro apolítico no sentido rigoroso do termo. É da essência do próprio teatro o ser político.

Dias Gomes

\section{A literatura e sua intertessitura} Atualmente fala-se em gêneros de fronteira, em trânsito entre áreas da cultura humana, em multiplicidade e intertextualidade. Neste sentido, BOSI (1997, p.19) escreve: Teria chegado o momento de acabar com esta pesada e canônica tradição segundo a qual literatura é literatura, linguagem de comunicação é linguagem de comunicação, e realizar, performativamente, a identidade profunda de ambas as atividades [...].

Com sua visão futurista constata que "o que está sucedendo cada vez mais, é a compresença, a fusão, esse desejo enorme de sair das gaiolas de uma prática compartimentada da cultura [para] entramos em outro paradigma pelo qual já não haveria distinções nem fronteiras entre ficção e não-ficção."

É patente em certas obras literárias de variados gêneros $a$ copresença entre ficção e a não ficção, a fusão de gêneros e de áreas da produção cultural da humanidade. O trânsito entre os aspectos

(*) Trabalho resultante da dissertação de mestrado intitulada "O dramático e o político: o encontro de Dias Gomes e Paulo Freire em A invasão", orientada pela Profa. dra. Enaura Quixabeira Rosa e Silva. 
literários e não-literários dessas obras parece dotá-las de uma maior motivação para fruí-las, refleti-las, analisá-las e recriá-las.

Neste sentido, CALvino vai além da concepção de intercâmbio entre gêneros e áreas quando, apresentando sua proposta de multiplicidade da literatura, escreve:

A literatura só pode viver se se propõe a objetivos desmesurados. Até mesmo para além de suas possibilidades de realização. [...] o grande desafio para a literatura é o de saber tecer em conjunto os diversos saberes e os diversos códigos numa visão pluralística e multifacetada do mundo. (1998, p.127-138).

Considerando a obra literária em geral como uma representação estética do social, CÂNDIDO (1985, p.20) apresenta a idéia dos sociólogos modernos de que a arte é social em dois sentidos: na influência que sofre dos fatores do meio e na influência que exerce sobre leitores, podendo provocar-lhes reflexões e mudanças de concepções, independente do grau de conscientização do público e dos atores, mas dependente do valor da obra.

Assim a primeira tarefa é investigar as influências concretas exercidas pelos fatores sócio/culturais [...] os mais decisivos se ligam à estrutura social, aos valores e ideologias, às técnicas de comunicação [...]. Assim, os primeiros se manifestam mais visivelmente na definição da posição social do artista, ou na configuração de grupos receptores; os segundos, na forma e conteúdo da obra; os terceiros, na sua fatura e transmissão. (idem, p.21)

Se, conforme CÂNDIDO, os fatores mais decisivos que influenciam as obras literárias se ligam à estrutura social, aos valores e ideologias, sendo portanto fatores políticos, o entremear de questões políticas com obras literárias não somente é possível, como está presente nas duas áreas em questão.

Neste sentido, o filósofo GramSCI (1978, p.11) faz a seguinte colocação: "Admitido o princípio de que, na obra de arte. deva-se buscar tão sòmente (sic) o caráter artístico, nem por isso é excluída a investigação de qual seja a massa de sentimentos, de qual seja a atitude diante da vida que circula na própria obra de arte." 
Concordamos em que a literatura não gera literatura, pois a partenogênese não acontece. Para haver germinação, fecundação e parto, é preciso a presença do elemento masculino, de um componente real, passional moral, histórico, revolucionário, enfim, das relações sociais. (GRAMSCI, 1978, p.11-13).

\section{A intertessitura da literatura dramática}

Segundo MOISÉs (1979, p.279), podemos dizer que entre os gêneros literários, o dramático é o que melhor permite trabalhar a realidade circundante, pois as ações realizadas por atores, contribuem para a representação concreta dos fatos narrados. E o texto dramático favorece, pela sua própria especificidade e características, a função catártica e a identificação com a realidade contextual e social.

Num outro sentido o teatro de Bertolt Brecht, usando do efeito de distanciamento, favorece a reflexão crítica sobre o enredo, sobre as características das personagens - que agem movidas por condicionantes sociais - atuando assim no consciente do leitor/espectador, provocando uma conscientização.

Segundo BRECHT (1978, p.55-57), "em peças de dramática das personagens devia efetuar-se no domínio do consciente do espectador, e não, como até este momento, no domínio do seu subconsciente."

O distanciamento enaltecido por Brecht assemelha-se ao distanciamento proposto nos textos político-pedagógicos do educador Paulo Freire, quando afirmam que a reflexão crítica do sujeito da educação se produz nos momentos em que se toma distância do objeto do conhecimento, da realidade circunstancial, para admirá-la e, admirandoa, decodificá-la, desmistificá-la e, posteriormente, transformá-la.

Uma das características do homem é que somente ele é homem. Somente ele é capaz de tomar distância frente ao mundo. Somente o homem pode distanciarse do objeto para admirá-lo. Objetivando ou admirando - admirar se toma aqui no sentido filosófico - os homens são capazes de agir conscientemente sobre a realidade objetivada. (FREIRE, 1980, p.25-6) 
Há portanto uma intertessitura do aspecto dramático do efeito do distanciamento com o aspecto político da ação pedagógica do admirar nos textos de Brecht e Freire.

Nessa linha de pensamento podemos encontrar textos não necessariamente artísticos, que trabalhando com outra linguagem jornalística, pedagógica, sociológica, política - oferecem oportunidade para se questionar os limites sutis entre a linguagem literária e a informativa. É o caso da produção pedagógico-política do educador Paulo Freire, eivada de um forte teor literário, como se pode perceber no texto abaixo:

Tive recentemente em Olinda, numa manhã como só os trópicos conhecem, entre chuvosa e ensolarada, uma conversa [...] com um jovem educador popular que, a cada instante, a cada palavra, a cada reflexão, revelava a coerência com que vive sua opção democrática e popular [...]. Enquanto andávamos pelas ruas daquele mundo maltratado e ofendido eu ia me lembrando de experiências de minha juventude em outras favelas de Olinda ou do Recife, dos meus diálogos com favelados e faveladas de alma rasgada. Tropeçando na dor humana, nós nos perguntávamos em torno de um sem-número de problemas. Que fazer, enquanto educadores trabalhando num contexto assim? (1996, p.82).

Parece indiscutível a literariedade desse texto. Ao situar conversa tão séria numa manhã entre chuvosa e ensolarada, Paulo Freire parece nos introduzir num romance, quando na verdade o que está mostrando são os problemas vividos pelo educador popular na sua difícil realidade. E a poeticidade permanece na personificação do mundo maltratado e ofendido, nas metáforas dos favelados $e$ faveladas de alma rasgada, e na expressão tropeçando na dor humana.

Em contrapartida, encontram-se em textos literários, e naquilo que particularmente nos interessa, em textos dramáticos, um teor político muito forte, sem que isso os descaracterize. É o que sucede na peça Gota d'água, de Chico Buarque e Paulo Pontes, na fala da personagem Egeu (p.53, Ato I), quando este explica a Jasão o drama do pagamento da casa financiada, para os credores de Creonte, 
os quais, provavelmente, o autor representa como uma metáfora dos mutuários do sistema habitacional brasileiro:

\section{Egeu}

Todos dando duro no batente

A fim de ganhar um ordenado

Mirradinho, contado, pingado...

Nisso aparece um cara sabido

Com um plano meio complicado

pra confundir o pobre fodido:

casa própria pela bagatela

de dez milhões, certo? Dez milhões

aos poucos, parcela por parcela, [...]

Bem, o trouxa fica fascinado...

Passa a contar tudo que é tostão,

Se vira pra tudo quanto é lado,

Que ter casa própria é uma ambição

decente. Então ele pega, sua, deixa de comer ... Livra cem, e vamos dizer, dorme na rua, larga a cachaça e não vê mais nem futebol. No fim do mês tá dando pra juntar as cem pratas sagradas Muito bem. O tempo vai passando E lá vêm as tachas caralhadas De juros, correção monetária e não sei mais lá quanto por cento...[...] $\mathrm{Um}$ ano depois, quando o jumento Juntou cem contos pra prestação Vai ver que com todos os aumentos, Os cem cruzeirinhos já não dão: A prestação subiu pra trezentos...

É uma situação dramática, em que o elemento trágico nasce das contradições existentes nas relações sócio-econômicas. Estão presentes no texto características da linguagem poética, não só pelas rimas, mas pela disposição harmoniosa e metafórica dos versos, com um conteúdo que, sendo profundamente político, retrata a situação de surpresas, tensão e mudanças repentinas em que vive mergulhada 
grande parte da população brasileira, em busca de resolver o problema de não ser dono de sua moradia.

E nessa linha de contradição, que só enriquece o trânsito entre diferentes aspectos da cultura, há textos literários, de todos os gêneros, eivados de conotações jornalísticas, pedagógicas, sociais, políticas, e dos mais variados aspectos da produção cultural.

Se considerarmos o gênero dramático como o que melhor representa a realidade sócio-política podemos concordar com críticos dramáticos como Anatol Rosenfeld que ao considerarem as funções da literatura em geral e deste gênero em particular, concordam

[...] com a opinião de que 'toda literatura que merece este nome encontra-se em oposição à sociedade a que pertence'.[...] a literatura é sempre, de uma ou de outra forma, expressão de valorizações múltiplas, entre as quais não deixam de manifestar-se também as político-sociais [...] Sobretudo o dramaturgo não pode furtar-se à tarefa de proporcionar aos espectadores, com certa frequiência, espetáculos perturbadores que satisfaçam precisamente por suscitar insatisfação, por revolverem as águas paradas do habitual conformismo satisfeito. (ROSENFELD, 1996, p.56)

Já na Grécia Antiga, dramaturgos como Eurípedes incluíam em suas peças temas sociais, com intenções claramente políticas de chamar a atenção para facções da sociedade vítimas de discriminação e opressão. É o caso dos estrangeiros, dos escravos e das mulheres, personagens de peças suas, nas quais o dramaturgo descreve a opressão, a discriminação e apresenta um sentido reivindicatório. GASSNER (1991, p.76) apresenta como exemplos desse fato as peças Medéia - onde se focaliza a discriminação que sofre o estrangeiro - e As Troianas - onde se percebe a opressão às mulheres do povo vencido.

Com PEACOCK (1968, p.199-200), podemos afirmar que o gênero dramático nasce da realidade social, a revive e reflete. Constitui-se numa interpretação dessa realidade através de imagens, diálogos e ações, nos quais tanto o elemento figurativo quanto o expressivo, tanto o conteúdo quanto a forma se entremeiam. As inúmeras variações das formas de teatro, do drama à comédia, 
segundo PEACOCK "têm todos sua maneira original de associar a forma dramática com certa visão da vida defendida por uma sociedade ou um indivíduo". O autor defende pois o caráter político da literatura dramática quando considera que

o 'drama' $[\ldots]$ pode ser o servo de um credo, uma estória simples mas comovente, uma análise de personalidade, um retrato de costumes, a proclamação de um sentimento subjetivo, um veículo para a conquista ou repúdio de uma fé, um conto de fadas ou fantasia, um 'provérbio', uma narração histórica, uma alegoria [...] (1968, p.199-200)

Diante da leitura de uma peça ou de sua representação teatral, o leitor/espectador faz uma avaliação dessas obras de arte, pautada tanto nas situações dramáticas de que se compõem, nas técnicas de dramaturgia utilizadas e no estilo do autor, quanto no desenvolvimento de uma idéia ou conteúdo ou nas emoções que desencadeia, frutos da catarse ou do efeito de distanciamento, que permitem uma purificação ou uma reflexão crítica sobre a temática abordada.

Conseqüentemente, é o jogo do conteúdo, das idéias trabalhadas, dos aspectos ideológicos com a organização da trama da peça que contribuem para sua apreciação por determinado tipo de público. Ou seja, o entrelaçamento desses dois aspectos - o dramático e o temático - que compõem a estrutura de uma peça é um dos fatores que contribuem para a aceitação dessa obra teatral pelo público.

O conteúdo, tema ou mensagem da peça é influenciado pela ideologia do autor, e representa sua perspectiva da realidade que o cerca, sendo, nesse caso, político. Há sempre um entremear dos aspectos dramáticos e políticos nesse tipo de produção literária.

\section{A intertessitura do dramático com o político-pedagógico em $A$ invasão.}

A partir das contribuições dos teóricos e críticos anteriormente citados, faremos o estudo da intertessitura dos aspectos dramáticos com os políticos na peça em questão.

O estudo das características dramáticas de $\boldsymbol{A}$ invasão se depara com a dificuldade de analisá-las apenas à luz da dramaturgia, 
pois o desenrolar de seu enredo é composto por fatos políticos que correspondem aos momentos de tensão dramática mais acentuada da peça. É o que se percebe nos três grandes momentos de clímax:

- O primeiro enfrentamento com a polícia, quando os invasores do prédio, usando como pano de fundo o velório do anjinho, afastam "os tiras", provocando a primeira ação intencionalmente coletiva dos invasores.

- O segundo enfrentamento com a polícia, momento também de tensão, de mudanças repentinas, de clímax, oportuniza a ação político-demagógica do deputado Deodato Peralva, que age mancomunado com a polícia, sob a coordenação "cênica" de Gorila.

- O assassinato de Mané Gorila que, despertando uma catarse coletiva, representa para os invasores a morte da opressão e da exploração mais imediatas, ao tempo em que representa mais uma ocasião para a implementação de um sentimento de grupo entre os invasores. A forma como comemoram esse assassinato - com uma coreografia coletiva - é dramática e política ao mesmo tempo.

Esses episódios causam tensão e suspense - características do texto dramático conforme explica PEACOCK (1968, p.200): "os acontecimentos e situações devem ser acompanhados por tensão, mudanças repentinas e um climax", ao tempo em que representa uma ação política de resistência à pressão do poder institucionalizado.

Em $A$ invasão, todo o enredo é perpassado por um clima de tensão, que vai desde o momento da invasão do prédio inacabado e abandonado até o desfecho - a ordem judicial permitindo a permanência dos invasores no local ocupado. Ao longo dessa trajetória, eivada de expectativas, surpresas e mudanças repentinas, os fatos da trama têm, quase todos, uma conotação política. Essa conotação política está presente não só nos momentos de enfrentamento coletivo com o poder institucionalizado, mas nos momentos de enfrentamento pessoal entre as personagens, cujas ações resultam de seus níveis de conscientização política.

O conceito de conscientização política usado neste artigo é de autoria do educador Paulo Freire, que em sua teoria da educação libertadora estuda o processo de formação da consciência crítica dos cidadãos, o papel do homem no mundo como sujeito de sua história e 
da apropriação de seu conhecimento e a questão da opressão como processo que estabelece uma relação antagônica entre opressores e oprimidos, sujeitos situados em pólos opostos numa relação de poder.

São estes diferentes níveis de conscientização das personagens de $A$ invasão, que norteiam suas visões de mundo e suas posturas de fuga, de acomodação ou de luta diante de sua situação de opressão. Níveis que vão desde a consciência semi-intransitiva - em que os indivíduos se encontram imersos em sua realidade circunstancial, e a ela se acomodam - passando pelo estágio de consciência ingênua - que já lhes permite enxergar sua realidade e fugir dela por meios às vezes individualistas e desorganizados chegando à consciência crítica - em que os sujeitos enxergam criticamente sua realidade circunstancial e procuram transformá-la de maneira organizada junto com seus pares.

A questão da opressão é focalizada por dramaturgos de renome no mundo hispano-americano como Ermínio Néglia, (Apud GADOTTI, 1996, p.617) que escreve:

Existem também obras dramáticas de maior envergadura artística que, embora tenham estreado antes da popularização da teoria de Freire, coincidem com ela na preocupação existencial dos autores pelos problemas da opressão. As coincidências devem-se ao impulso coletivo hispano-americano de colocar questões cruciais, que são também as de todo o povo imerso no mundo da opressão.

Nesse sentido, não só o conteúdo político é enfocado em "obras dramáticas de maior envergadura artística" como "a teoria de Freire e os problemas da opressão" aparecem implícitos nos conteúdos dessas obras dramáticas, entrelaçando, portanto, o dramático com o político e com o pedagógico.

O tema opressão é também focalizado por Boal que, com a sua Poética do Oprimido, cria o Teatro do Oprimido em que o povo passa de espectador passivo do espetáculo teatral a ator, a transformador da ação dramática. A Poética do Oprimido propõe a própria ação. (BOAL,1975, p.126). Do mesmo modo, Brecht, em sua poética, propõe uma conscientização do espectador, para que saia do teatro propenso a transformar a realidade social. 
Na peça $A$ invasão, a situação de opressão e marginalização em que vivem os favelados invasores do prédio, em contraposição aos seus antagonistas que detêm o poder de expulsá-los do local ocupado, constitui o tema central. Na intrincada rede dos fatos da trama, "as tensões, mudanças repentinas e clímax" estão correlacionados com esse significado central, proveniente do seu conteúdo político.

Este clima de constante tensão diante do perigo de uma provável expulsão do local em que ora habitam está indicado em algumas rubricas cênicas e alguns diálogos da peça, do primeiro ao terceiro atos. Logo no começo do primeiro quadro, o autor coloca em nota de rodapé, na página 18: "O tom de representação durante todo esse quadro deve ser, necessariamente, abafado, a meia voz, num clima de suspense."

$\mathrm{E}$ as falas das personagens confirmam esse clima (p.19-20), quando, no início da peça, elas vão invadindo o prédio sorrateiramente, quase que uma a uma, sussurando entre si. É o caso das personagens que primeiro chegam à construção abandonada, Bené, Lula e sua mãe:

Bené

(Num tom abafado.) Por aqui. Podem vir.

Lula

Fala baixo, mãe! O guarda pode ouvir...

A expressão fala baixo, mãe denota a preocupação em não despertar a atenção dos guardas que vigiam o quarteirão onde se localiza o prédio invadido. Do mesmo modo, Bola Sete e Lindalva, já ocupantes do prédio, conversam com vozes abafadas, assustados e cautelosos:

[...] As vozes de Bola Sete e Lindalva vêm do $1^{\circ}$ andar, abafadas também, receosas.

Lindalva

(Assustada.) Tu ouviu? Tem gente aí!

Bola Sete

Será o guarda?...

(Bola Sete surge no apartamento da esquerda do primeiro andar, levantando-se cautelosamente [...] ergue também a vista para os andares superiores, cautelosamente. 


\section{DE DIAS GOMES}

As personagens Justino, Santa, Malu, Tonho e Rita revelam o cuidado em não serem descobertas pelo guarda, agindo de forma receosa e intimidada. É o que relata a rubrica cênica da pagina 20 , Ato I quadro 1:

No andar térreo, surgem Justino, Santa, Malu, Tonho e Rita. Vêm também carregados de trouxas, sendo que Santa traz ao colo uma criança de meses, adormecida e embrulhada em panos. Todos cinco têm a mesma expressão de atordoamento. Por alguns instantes ficam sem saber o que fazer, olhando para os lados, receosos e intimidados.

No diálogo da página 26 desse mesmo quadro, Tonho, preocupado, referindo-se à criança, faz uma pergunta a Santa que lhe responde com outra pergunta: Se ele danar a chorar? Ao que Santa responde: Que tem? E Tonho, explicando o motivo de sua preocupação, completa: O guarda...íamos ser descobertos.

O clima de tensão volta a se acentuar, na cena do primeiro embate com a polícia, que começa com o grito de Bola Sete: "Pessoal, eles vêm aí!" [...] (Ato I, Quadro 2, p.61): (Entra correndo, vem à frente, grita para cima.) Tão aí! Os tiras tão aí![...]

Tonho confirma: Parou um carro aí em frente. Diz que é da polícia .Carro que pára em frente a prédio invadido por "sem teto" só pode ser carro da polícia.

$\mathrm{Na}$ cena do segundo enfrentamento com a polícia a tensão novamente se acentua. E é outra vez Bola Sete quem dá o alarme:

Súbito, ouvem-se as sirenas de vários carros da Polícia. Tocados por uma mesma mola, todos se póem à escuta. Bola Sete e Lindalva, no $1^{\circ}$ piso, olham na direção do ruído.

Bola Sete

[...] Vão cercar o quarteirão. É tira que não é vida! Dessa vez eles vieram pra valer!

(Grita para baixo.) Minha gente, se preparem que o negócio agora vai ser feio![...] 

batalhão!

Rita, que observa a cena, confirma, assustada: E agora é um

Os dois tiras invadem a cena. O primeiro tira, o segundo tira e mais dois, chefiados todos por um inspetor. Entram abruptamente, dispostos a tudo. (Ato II, Quadro 3, p.89-90)

E assim, os invasores continuam convivendo com o suspense, com a tensão dramática causada pelo perigo iminente da expulsão do prédio, ao longo de toda a peça. Esse suspense, essa sensação de medo, de preocupação, se percebem nas falas de algumas personagens em diferentes momentos. Por exemplo, na fala de Lula:

[...] Soube ontem que o Juiz tá pra assinar a ordem de despejo. Vão tocar a gente daqui pra fora de hoje pra amanhã.[...] Rafael me disse. Informação segura. A coisa tá por horas. (Ato II, Quadro 5, p. 21-2).

Também no diálogo entre Mané Gorila e Isabel percebe-se a preocupação desta com a ameaça de despejo, ameaça que em nada desfavorece a Gorila mas que acirra o medo e a insegurança de Isabel: (Ato II, Quadro 3, p.70.)

Isabel

[...] o advogado da União dos Favelados está vendo se arranja uma ordem do juiz, um troço de nome complicado pra gente ficar aqui. Mas não é nada seguro. De uma hora pra outra eles tão aí pra botar a gente pra fora.

Gorila

Tou sabendo que não passa de hoje. [...]

Isabel

Quem disse?

Gorila

Eu que sei.(Respira fundo).

O desfecho, um elemento da dramaturgia clássica, se constitui de uma ordem judicial que autoriza a permanência dos invasores na obra em construção. É um desfecho político, pois, como tal, é o resultado da luta política empreendida por Lula, Rafael e provavelmente pela União dos Favelados. Político também é o nó 


\section{DE DIAS GOMES}

dramático - questão habitacional da camada popular brasileira, como político é o conteúdo da trama - expectativa de resolver o problema de moradia dos invasores do prédio. Nó dramático, conteúdo e desfecho, são elementos dramáticos do texto de $A$ invasão. Luta política pela posse do teto, questão habitacional da camada popular brasileira são elementos políticos do texto da peça. Distingui-los, separá-los, mesmo para estudo, torna-se quase impraticável.

O entremear dos aspectos dramáticos com os aspectos políticos desse texto é percebido, também, nas características das personagens, expressas através de suas ações e réplicas, representadas nos diálogos e descritas nas rubricas cênicas.

Ao descrever a personagem Lula, por exemplo, numa das primeiras rubricas cênicas a ele referentes, o autor o faz de forma dramática e política ao mesmo tempo. Constrói a personagem de modo a predestinar sua atuação, pressentindo-se, desde o início da leitura da peça, o papel político e dramático que deverá exercer na trama:

(Sente-se nele um desejo de afirmação, de quebrar as cadeias que o prendem a condições e concepções de vida primárias. Uma consciência ainda embrionária. de um papel mais importante na sociedade. Seu conflito com o meio é flagrante. Seu processo de libertação também parece evidente.) (p.22)

"O conflito com o meio" vai gerar sua ação dramática na peça e sua atuação política determina-lhe um papel significativo na resolução desse conflito. $O$ conflito desta personagem simultaneamente dramático e político - vai determinar sua ação, seu movimento em busca da "libertação das cadeias que o prendem a condições e concepções de vida primárias".

Por sua vez, a figura de Mané Gorila é uma construção simbólica. Apresentando-o "com seu andar gingado, sua fala macia que quando ameaça corta como navalha", com sua agressividade disfarçada, o autor constrói uma personagem forte e dúbia ao mesmo tempo, cuja oscilação não é só estética, mas política. Personagem que age através de estratégias e estratagemas, e que representa muito bem o duplo papel de explorador e explorado. Figura grotesca, oscilante entre dois mundos, entre dois contextos e duas "morais": a moral dos 
opressores, a quem é subserviente, e a moral dos oprimidos, a quem explora assumindo atitudes protetoras e paternalistas.

A contradição de Mané Gorila é representada, inclusive, através de sua atitude condescendente e afetiva para com as crianças. Esta característica da personagem aparece quando Isabel pergunta sobre "a adoção" dos filhos da irmã do profeta e quando esta declara a Justino: "Criança tem tudo dele." Está presente também nas rubricas cênicas da página 76, Ato II, Quadro 3:

Dois garotos descem dos andares superiores, gritando: "Mané Gorila, me dá uma prata! Mané Gorila, me dá uma prata!"

Gorila

(Tira do bolso dinheiro e distribui entre os garotos.) Tome lá. (Sai, seguido dos garotos, batendo paternalmente na cabeça deles.)

Profeta, por sua vez, apresenta-se como outra figura personagens menos apregoa valores morais compartilhados pelas personagem, como a constíntizadas da peça. O que o autor diz da página 25, Ato I, Quadro 1 .

(É um mulato de pequena estatura, longa barba negra, cabeleira hirsuta. Veste calças escuras e surradas. A camisa também escura por fora das calças, sandálias, porta-se com a dignidade e a serenidade de um verdadeiro profeta. É um neurótico, não há dívida, mas entre a gente humilde que o cerca, infunde, se não algum respeito, pelo menos um certo temor.)

Entretanto, a personagem o Profeta não aproveita da força desse simbolismo, diante de "seu público", para refletir com ele sobre a realidade de opressão em que vive. As personagens que compõem esse público, conforme diz o autor, ao tempo em que o temem, o admiram. Pode-se perceber isso na réplica de Santa a Tonho, na mesma página, Ato e quadro: "Mexa com ele não. Beato anda sempre metade com Deus, metade com o Cão."

A construção da fala de Santa caracteriza a contradição da personagem o Profeta, que mereceria do autor um papel dramático 
mais relevante na trama da peça. Politicamente, também, poderia Ter um papel mais atuante, no sentido de aproveitar o seu discurso religioso para uma reflexão e uma posterior conscientização dos favelados, que talvez o ouvissem e com ele agissem na luta em prol da resolução do problema comum a todos eles. Como se vê, o papel dramático do Profeta coincide com o seu papel político na peça.

O entremear do dramático com o político aparece também nas ações e falas da personagem Bola Sete, nos momentos de sua atuação mais decisiva:

- quando parece compreender o clima de tensão favorável aos favelados e, tirando proveito disso, age no sentido de expulsar os tiras do prédio invadido, usando do argumento do velório do anjinho. É uma ação dramática e política ao mesmo tempo.

- na coreografia com que ele e Lindalva comemoram, dançando, o sucesso de seu samba no mundo das composições musicais. Tal coreografia contagia as outras personagens que associam essa comemoração à da morte de Mané Gorila, começando todos a cantar e a dançar ao som do samba gravado em disco da autoria do próprio Bola Sete. É uma comemoração carregada de uma estética dramática e, simultaneamente, de um significado político.

Quanto à personagem Deodato Peralva, o autor a descreve como sendo: "moço ainda. Bem-falante, demagogo sem qualquer limitação" (p.92). Constrói-no com uma heterogeneidade característica dos papéis dramáticos e políticos que desempenha:

- o papel de agente vetor da mudança do destino de Malu e do afastamento do par amoroso da peça - Malu e Lula;

- contraditoriamente, o papel de contribuir para a posterior reaproximação desse par, com sua ação de abandonar a jovem, após sua derrota eleitoral e seu provável desinteresse por ela;

- o papel de causar surpresas e situações de clímax na peça, aparecendo num dos momentos de tensão, e enfrentando a polícia; o papel político de levantar expectativas entre os favelados que vêem no discurso demagógico de Deodato uma esperança. A esperança dos desesperados que precisam se iludir na busca de uma perspectiva de salvação e esperar 
contra todas as desesperanças, para que a própria esperança não ceda lugar ao desespero.

A personagem Rafael tem um significado tanto dramático quanto político na trama da peça, pois representa, juntamente com Lula, o núcleo de resistência à engrenagem política que mantém a situação de opressão e miséria em que vive o grupo de favelados. Rafael é uma personagem especial. Literariamente é a metáfora da ideologia defendida pelo autor, e citada na fala das demais personagens, principalmente na fala de Lula. Sem aparecer concretamente no texto, tem, entretanto, um papel bastante significativo no enredo. É o articulador do abaixo-assinado que Lula faz correr entre os favelados, e que, uma vez entregue ao juiz, garante o despacho favorável à permanência destes no prédio invadido, solução temporária para o problema vivido por todos.

Através da característica metafórica de Rafael, o elemento literário do texto da peça mais uma vez se entremeia com o elemento político de seu conteúdo, confirmando o fato de ser o texto de $A$ invasão uma produção plena desses dois componentes que, no desenrolar da trama, não se excluem, mas se interdependem.

Continuando no sentido da caracterização das personagens que, em suas ações, entremeiam o aspecto dramático com o político, vemo-nos diante da figura de Isabel, cujas ações e réplicas, nos momentos de tensão da peça, fazem com que sua atuação política aconteça nas ocasiões de clímax, em que Isabel tem uma forte atuação dramática. Assim acontece na cena do enfrentamento com os tiras - já registrada em capítulos anteriores - e na cena do assassinato de Mané Gorila, quando, drasticamente, diz a Tonho: "Rapaz...você está perdido!" E, sendo a única a Ter coragem de chegar bem perto do corpo, depois de constatar que o opressor está realmente morto, declara: "Tá morto mesmo. Se não fosse covardia, eu ainda cuspia nele." (Ato III, p.170-71)

Ao apresentar Isabel, o autor escreve na rubrica cênica da página 23, do Quadro 1, Ato I: "é uma mulher forte, decidida, afeita ao trabalho duro. Sua coragem - uma espécie de valentia animal e pouco consciente - é capaz de levá-la a rasgos heróicos."

Também em seu diálogo com Malu, em que é comentada a péssima alimentação do irmãozinho da jovem nordestina - mingau de 


\section{DE DIAS GOMES}

farinha e água - as observações e interrogações de Isabel têm uma conotação política, de crítica, e uma conotação dramática, de surpresa e estranhamento.

Quanto às rubricas cênicas, aquelas que apresentam um maior imbricamento do dramático com o político, estão registradas no último ato da peça quando, após o assassinato de Mané Gorila, ouvem-se vozes gritando: "Mataram Mané Gorila!"

(Os favelados começam a surgir de todos os lados, tomados de incredulidade. No fundo, cada um deles alimentava uma sede insaciada de vingança contra Mané Gorila. A contemplação de seu corpo estendido ao solo, morto, faz aparecer em todos os rostos a alegria sádica de desforra, misturada ao temor gerado pelo fato de cada um deles sentir-se co-autor do crime. E, mesmo morto, Mané infunde temor.) p.170

Esta cena é narrada de maneira patética, quando descreve a incredulidade e "a alegria sádica de desforra, misturada ao temor gerado" pela co-autoria intencional e coletiva do crime. Este temor representa um medo das consequiências policiais e jurídicas de um ato, cometido psicologicamente de forma coletiva, fruto de seus desejos de fazer justiça com as próprias mãos. Ação que é intencional e, até onde seu nível de conscientização lhes permite, política.

A cena final da peça, descrita na última rubrica cênica (Ato III p.175), perpetuando a eufórica vingança dos oprimidos contra o opressor e representando, portanto, uma vitória política, é comemorada de forma coreograficamente estética, embora esteticamente grotesca:

Os tiras vêem, por fim, o corpo de Mané Gorila. Debruçando-se sobre ele, verificam que está morto e olham em torno à procura do assassino. Mas, com exceção de Malu e Lula, que de mãos dadas esperam Rafael, todos os outros dançam alucinadamente, tomados por um verdadeiro delírio. Como se diante do corpo sem vida de Mané Gorila, se sentissem vingados de todos os Manés Gorilas.

De acordo com essa rubrica, a euforia da vitória embriaga de tal forma os favelados que, neste momento de clímax, vivenciando sua 
catarse, ignoram os tiras, ou subestimam sua presença, tanto quanto Malu e Lula que, num momento de tranqüila união, "de mãos dadas esperam Rafael ". É, pois, o gênero dramático iluminando a questão política, a qual se apresenta "de forma estética e, portanto, sujeita a toda a sorte de metamorfose" (MOISÉs,1986,p.279).

A vantagem da combinação do gênero dramático com o tema político é que a função catártica ou a função de distanciamento e conscientização que se exerce sobre o público são mais imediatas, pois se efetivam através da fala e das ações de pessoas (personagens) presentes e atuantes num contexto social e político.

$\mathrm{Na}$ sua incessante busca de representar a realidade social de sua época, a produção de Dias Gomes apresenta-se como teatro fundamentalmente político que, não abandonando os aspectos dramáticos, visa atingir níveis mais profundos da consciência do público através da conscientização de personagens fictícias, representando a realidade a sua volta.

O texto de $A$ invasão revela características de um teatro contemporâneo que estabelece contatos entre a arte e a vida indo além da estética tradicional. E como não poderia deixar de ser, em se tratando de um teatro político, possui ainda características de um teatro social, na medida em que, neste, "o teatro toma consciência de sua função dentro da sociedade, sem encarnar uma ideologia precisa e sem o propósito de converter ninguém a essa ou àquela causa." (MAGALDI, 1993, p.105).

Nesse sentido, a forma dramática de $A$ invasão condiciona e é condicionada pelo ser social representado nas personagens, cuja ação se efetiva em meio aos conflitos de uma sociedade dividida em classes antagônicas, pois "[...] Está claro que toda grande dramaturgia, pela funda impregnação humana, tem garra social. (id., p.105).

Neste texto dramático, a ação das personagens nos momentos mais decisivos de sua trama permite-nos constatar esta garra social. Permite-nos observar o componente social condicionando e alterando a trama.

Se esse componente político determina o desenrolar da trama, há, portanto, na peça, uma interdependência desses dois aspectos, uma interação da literatura dramática com um tema sóciopolítico, um movimento dialético ligando os aspectos dramáticos aos políticos, uma intertessitura do dramático com o político. 


\section{Referências Bibliográficas}

BOAL, Augusto. Teatro do oprimido e outras poéticas políticas. Rio de Janeiro: Civilização Brasileira, 1975.

BOSI, Alfredo. As Fronteiras da Literatura. In: AGUIAR, Flávio et al. Gêneros de fronteiras: cruzamento entre o histórico e o literário. São Paulo: Xamã,1997.

BRECHT, Bertolt. Estudos sobre teatro. Trad. Fiama Paes Brandão. Rio de Janeiro: Nova Fronteira, 1978.

BUARQUE DE HOLANDA, Chico \& PONTES. Paulo. Gota d'água. 22. ed. Rio de Janeiro: Civilização Brasileira, 1993.

CALVINO, Italo. Seis propostas para o próximo milênio: lições americanas. Trad. Ivo Barroso. São Paulo: Companhia das Letras, 1998.

CÂNDIDO, Antônio. Literatura e sociedade: estudos de teoria e história literária. 7. ed. São Paulo: Nacional,1985.

FREIRE, Paulo. Conscientização: teoria e prática da libertação: uma introdução ao pensamento de Paulo Freire. 3. ed. São Paulo: Moraes, 1980.

FREIRE, Paulo. Pedagogia do oprimido. 17. ed. Rio de Janeiro: Paz e Terra, 1987.

CASSNER, John. Mestres do teatro I. Trad. Alberto Guzic e J. Guinsburg. São Paulo:Perspectiva, 1991 (Coleção estudos, v.36).

GOMES, Dias. A Invasão: peça em três atos e cinco quadros. 5. ed. Rio de Janeiro: Bertrand Brasil, 1998.

GRAMSCI, Antonio. Literatura e vida nacional. Trad. Carlos Nelson Coutinho. 2. ed. Rio de Janeiro: Civilização Brasileira ,1978B.

MAGALDI, Sábato. Iniciação ao teatro. São Paulo: Ática, 1998.

MOISÉS, Massaud. A criação literária: prosa. 12. ed. São Paulo: Cultrix, 1979.

NÉGLIA, Ermínio G. Paulo Freire e sua aplicação ao teatro. In: GADOTTI, Moacir, (Org.) Paulo Freire: uma biobibliografia. São Paulo: Cortez, Instituto Paulo Freire: Brasília - DF: UNESCO,1996. 
PEACOCK, Ronald. Formas de literatura dramática. Trad. Bárbara Heliodora. Apresentação Paulo Francis. Rio de Janeiro: Zahar Editores, 1968.

ROSENFELD, Anatol. O mito e o herói no moderno teatro brasileiro. 2. ed. São Paulo: Perspectiva, 1996 (Coleção Debates; 179). 